Review

\title{
The in Vitro Antimicrobial Efficacy of Propolis against Four Oral Pathogens: A Review
}

\section{Nadine Michèle Waldner-Tomic ${ }^{1,4}$, Rosmarie Vanni ${ }^{2,4}$, Georgios N. Belibasakis ${ }^{3}$, Thomas Thurnheer ${ }^{3}$, Thomas Attin ${ }^{4}$ and Patrick R. Schmidlin ${ }^{4, *}$}

1 Private Practice, Zurich, Switzerland; E-Mail: drwaldner@ zuerismile.ch

2 Private Practice, Männedorf, Switzerland; E-Mail: rosyvanni@hotmail.com

3 Section for Oral Microbiology and Immunology, Institute of Oral Biology, Center of Dental Medicine, University of Zurich, Plattenstrasse 11, CH 8032 Zürich, Switzerland;

E-Mails: George.Belibasakis@zzm.uzh.ch (G.N.B.); Thomas.Thurnheer@zzm.uzh.ch (T.T.)

4 Clinic of Preventive Dentistry, Periodontology and Cariology, Center of Dental Medicine, University of Zurich, Plattenstrasse 11, CH 8032 Zürich, Switzerland;

E-Mail: Thomas.Attin@zzm.uzh.ch

* Author to whom correspondence should be addressed; E-Mail: Patrick.Schmidlin@zzm.uzh.ch; Tel.: +41-44-634-3284; Fax: +41-44-634-4308.

Received: 15 May 2014 / Accepted: 18 June 2014 / Published: 21 July 2014

\begin{abstract}
This study screened the available evidence for the in vitro antimicrobial efficacy of propolis, a natural herbal resin bee product, against a selection of three bacterial species of relevance to oral diseases. For this purpose, papers dealing with laboratory studies assessing minimum inhibitory concentration (MIC), minimum bactericidal concentrations (MBC) or the agar diffusion method to analyze the antimicrobial properties of propolis on three oral pathogens (S. mutans, $P$. gingivalis, $F$. nucleatum) and a yeast (C. albicans) are reviewed. Overall, a positive antimicrobial effect could be shown. However, when compared to the commonly used control substances (e.g., specific antibiotics, antiseptics and antifungals), propolis appeared less effective, depending on the bacterial strain, and required higher concentrations than the control substances, in order to show a measurable effect. Nevertheless, propolis as a natural herbal resin bee product can be considered as a natural antiseptic agent within the range of other herbal products, like sanguinarine. Therefore, it may be a valuable compound of non-synthetic, natural origin for patients seeking complementary agents and alternatives for "hard" chemicals.
\end{abstract}

Keywords: propolis; antimicrobial activity; biofilm; in vitro; caries; periodontitis 


\section{Introduction}

Bacteria are recognized to be a main causative factor for the development of periodontitis and caries. It has been shown that professional plaque control will thus prevent disease initiation and stop its progression. Thus, the main treatment target remains the effective reduction of the supra- and subgingival pathogenic flora, mostly by mechanical means. However, a variety of chemical means, like antibiotics and antiseptics, have been introduced as an adjunct to mechanical therapy [1,2]. Whereas the use of antibiotics is warranted in certain cases, especially in aggressive cases or patients with AN insufficient response to non-surgical therapy, it is associated with certain risks, notably the development of antibiotic resistance in various bacterial species [3]. The administration of antimicrobial agents as a quick and inexpensive means of supporting mechanical periodontal debridement is therefore still worth consideration [4]. Alongside well-investigated and established chemicals frequently used in gingivitis/periodontitis prophylaxis and treatment protocols, like chlorhexidine or iodine, natural products may represent a suitable alternative, exhibiting less or no side effects [5]. Among them, herbal bee products, like honey and propolis, have a great potential to be used as adjuncts to mechanical periodontal treatment and infection control, as well.

Propolis is a honeybee product, which is used to cover hive walls and fill gaps. Bees collect the resin-like product from cracks in the bark of trees and leaf buds [6,7]. Thereby, propolis does not only act as a structural compound, but is mainly responsible as a chemical agent for the safety of honeycombs, especially against microorganisms [8-10]. The chemical composition of propolis is highly variable and depends on the local flora at the site of collection and on the season of collection [11-13]. It is a lipophilic, resinous material collected from living plants, which is mixed with the enzyme, beta-glycosidase, present in the bees' saliva, partially digested and added to beeswax to form the final product [14]. Despite potential intrinsic differences, which may depend on the origin, it has been proven that most propolis variants have a wide range of biological therapeutic effects, such as antimicrobial, antifungal and antiviral activity $[10,15,16]$. Therefore, sufficient evidence is available in the literature to justify propolis as a good candidate adjunct to prevent or treat infectious diseases. Several laboratory studies exist, which assessed the antimicrobial potential of propolis using different in vitro test systems in order to evaluate the potential to inhibit the bacterial growth (bacteriostasis) or to induce bacterial death (bactericidal effect). To measure this potential, several evaluation methods are available, e.g., simple agar diffusion tests or dissolution assays. The latter determine either the minimum inhibitory (MIC), the minimum bactericidal concentrations (MBC) or agar diffusion tests, which, in principle, visually or optically assess the inhibition of bacterial growth. These tests are therefore commonly used to determine the potential of the agents and to classify them in relation to alternative chemical substances (controls). Antimicrobials are usually regarded as bactericidal, if the MBC is not more than four times the MIC [17]. Based on microbiological data derived from such assays, it has been suggested that propolis may even be of clinical value [18,19]. However, a systematic evaluation on the antimicrobial effects of propolis on bacterial species relevant to oral diseases and dentistry in general is still lacking.

This review therefore aimed to evaluate the evidence for the laboratory efficacy of propolis against a selection of three bacterial species with a high association with periodontitis and caries ( $S$. mutans, 
P. gingivalis, $F$. nucleatum) and a yeast (C. albicans). For this purpose, articles published in between 1960 and 2013 were screened.

\section{Materials and Methods}

\subsection{Search Strategy}

In order to conduct a review of the data published on the specific subject of interest, a literature search of the U.S. National Library of Medicine (PubMed) was performed. Articles from the inception of these databases up to and including June, 2013, were considered. The following strategy was qpplied: ("anti-bacterial agents"[MeSH Terms] OR ("anti-bacterial"[All Fields] AND "agents"[All Fields]) OR "anti-bacterial agents"[All Fields] OR "antibacterial"[All Fields] OR "anti-bacterial agents"[Pharmacological Action]) OR ("anti-infective agents"[MeSH Terms] OR ("anti-infective"[All Fields] AND "agents"[All Fields]) OR "anti-infective agents"[All Fields] OR "antimicrobial"[All Fields] OR "anti-infective agents"[Pharmacological Action]) OR ("anti-infective agents"[MeSH Terms] OR ("anti-infective"[All Fields] AND "agents"[All Fields]) OR "anti-infective agents"[All Fields] OR "antiinfective"[All Fields] OR "anti-infective agents"[Pharmacological Action]) OR ("disinfection"[MeSH Terms] OR "disinfection"[All Fields]) OR bactericidal[All Fields] OR bacteriostatic[All Fields] AND ("propolis"[MeSH Terms] OR "propolis"[All Fields]).

\subsection{Study Selection}

In the first step, two reviewers (the first and second author) independently screened all titles and then the abstracts of the electronic search and assessed them for possible inclusion in the review. All potentially eligible studies were ordered, and their full texts were assessed. Only studies written in English, German, French and Italian were included. Studies reporting on animal, gynecological, laryngological and dermatological experiments were excluded. Any disagreement concerning inclusion was resolved by discussion.

\subsection{Eligibility Criteria for Studies}

After reading the full text of the selected studies, the assessed bacterial taxa assessed and the methodologies used were recorded and the data were resumed in tables. Only studies were included that used the MIC, MBC or the agar diffusion assays and that investigated the effect of propolis on $S$. mutans, $P$. gingivalis, $F$. nucleatum or $C$. albicans.

\section{Results}

\subsection{Search Results}

From the 1,373 titles initially obtained from the literature search, 171 full texts were assessed. Eightysix articles were excluded because they were considering animal or dermatological studies. In the next step, 57 articles were excluded mainly for the following reasons: 
- The requested laboratory method was not assessed (i.e., no MIC/MBC or agar diffusion evaluation);

- $\quad$ None of the requested bacteria were assessed.

Finally, 28 original articles were analyzed that matched the inclusion criteria with regards to the three microbiological evaluation methods (Tables 1-4). From each study, the respective results were identified and recorded, accordingly. The mean values and ranges (minimum and maximum values) were provided, where applicable.

\subsection{Agar Diffusion Method}

Table 1 provides a summarized data set regarding the agar diffusion method. In general, the use of propolis resulted in smaller inhibition zones than the respective control media. No available data were found for F. nucleatum. In the case of $S$. mutans, the mean values of the inhibition zones were about $60 \%$ smaller than those of the control groups. The substances commonly used as controls in these studies were chlorhexidine and sanguinarine. The inhibition zone for propolis ranged from 0.2 to $22 \mathrm{~mm}$, whereas for the control groups, these zones ranged from 25 to $28 \mathrm{~mm}$. For $C$. albicans, the mean value for the zone of inhibition accounted for about $50 \%$ of the control groups. The control substances commonly used were chlorhexidine, itraconazole and ketoconazole. The inhibition zone for propolis ranged from 0.8 to $14 \mathrm{~mm}$, whereas the inhibition for the control groups ranged from 16 to $20 \mathrm{~mm}$.

\section{3. $M B C$ and $M I C$}

The results of the $\mathrm{MBC}$ evaluation indicated that propolis generally did not act as effectively as the compared control substances (Table 2). For S. mutans, the required mean MBC was almost 100-times higher than that of the control group. The control substance in this case was chlorhexidine, vestitol and neovestitol. The range of the MBC of propolis was very wide, spanning from $6.25 \mu \mathrm{g} / \mathrm{mL}$ to more than $1,600 \mu \mathrm{g} / \mathrm{mL}$. One study showed that propolis exhibited an antimicrobial effect on C. albicans, which was even greater than the control substance, chlorhexidine [21].

In Table 3, the result of studies assessing the MIC is provided. Once again, it could be shown that the effect of propolis was lower than the control substances, especially when $S$. mutans and $P$. gingivalis were tested. The MIC for $S$. mutans was comparable to the ones obtained by the corresponding control groups. The mean values of the MIC of propolis ranged from 0.5 to $12,500 \mu \mathrm{g} / \mathrm{mL}$, whereas those of the control groups ranged from 0.015 to $37,500 \mu \mathrm{g} / \mathrm{mL}$, respectively. For $F$. nucleatum and C. albicans, the mean values of the MIC were only approximately twice as high as the MICs of the control groups. For $P$. gingivalis, however, the MIC of propolis was about 360=times higher than the MIC of the control groups. 
Table 1. Results of the agar diffusion tests (inhibition zones in $\mathrm{mm}$ ) to evaluate propolis and control compounds (indicated with different superscript letters).

\begin{tabular}{|c|c|c|c|c|c|c|c|c|c|c|c|c|c|c|c|c|c|c|c|c|c|c|c|c|}
\hline \multirow{3}{*}{ Ref. } & \multicolumn{6}{|c|}{ S. mutans } & \multicolumn{6}{|c|}{ P. gingivalis } & \multicolumn{6}{|c|}{ F. nucleatum } & \multicolumn{6}{|c|}{ C. albicans } \\
\hline & \multicolumn{3}{|c|}{ Propolis } & \multicolumn{3}{|c|}{ Control } & \multicolumn{3}{|c|}{ Propolis } & \multicolumn{3}{|c|}{ Control } & \multicolumn{3}{|c|}{ Propolis } & \multicolumn{3}{|c|}{ Control } & \multicolumn{3}{|c|}{ Propolis } & \multicolumn{3}{|c|}{ Control } \\
\hline & Min & Mean & Max & Min & Mean & Max & Min & Mean & Max & Min & Mean & $\operatorname{Max}$ & Min & Mean & $\operatorname{Max}$ & Min & Mean & $\operatorname{Max}$ & Min & Mean & $\operatorname{Max}$ & Min & Mean & Max \\
\hline [34] & 10 & 12 & 13 & & & & & & & & & & & & & & & & 9 & 11 & 13 & & & \\
\hline$[35]$ & & 20 & & $\mathrm{a}$ & 28 & & & & & & & & & & & & & & & 14 & & $\mathrm{~b}$ & 20 & \\
\hline$[36]$ & 5.5 & 5.9 & 6.3 & & & & & & & & & & & & & & & & & & & & & \\
\hline$[25]$ & & 2 & & & & & & 3.4 & & & & & & & & & & & & 0.8 & & & & \\
\hline [37] & & 22 & & $\mathrm{c}$ & 27.6 & & & & & & & & & & & & & & & 10.4 & & $\mathrm{c}$ & 19 & \\
\hline$[38]$ & & 13 & & $\mathrm{c}$ & 25 & & & & & & & & & & & & & & & 10 & & $\mathrm{c}$ & 16 & \\
\hline [39] & & 15 & & $\mathrm{a}$ & 28 & & & & & & & & & & & & & & & 13 & & $\mathrm{~b}$ & 20 & \\
\hline$[40]$ & & & & & & & & & & & & & & & & & & & & 14 & & $\mathrm{~d}$ & 16 & \\
\hline$[41]$ & 0.2 & 0.3 & 0.4 & & & & & & & & & & & & & & & & & & & & & \\
\hline$[42]$ & & & & & & & 18 & 21.5 & 25 & & & & & & & & & & & & & & & \\
\hline Mean & & 11.3 & & & 27.1 & & & 12.45 & & & & & & & & & & & & 10.5 & & & 18.2 & \\
\hline
\end{tabular}

(a) Sanguinarine; (b) itraconazole; (c) chlorhexidine; (d) ketoconazole; (e) $\mathrm{CaOH2}$; (f) camphorated paramonochlorophenol; (g) formocresol; (h) fluconazol; (i) meropenem; (j) penicillin G; (k) penicillin; (l) miconazole; (m) tetracycline; (n) metronidazole; (o) erythromycin; (p) clindamycin. 
Table 2. MBC (minimal bactericidal concentration; $\mu \mathrm{g} / \mathrm{mL}$ ) of propolis and control compounds (indicated with different superscript letters).

\begin{tabular}{|c|c|c|c|c|c|c|c|c|c|c|c|c|c|c|c|c|c|c|c|c|c|c|c|c|}
\hline \multirow{3}{*}{ Ref. } & \multicolumn{6}{|c|}{ S. mutans } & \multicolumn{6}{|c|}{ P. gingivalis } & \multicolumn{6}{|c|}{ F. nucleatum } & \multicolumn{6}{|c|}{ C. albicans } \\
\hline & \multicolumn{3}{|c|}{ Propolis } & \multicolumn{3}{|c|}{ Control } & \multicolumn{3}{|c|}{ Propolis } & \multicolumn{3}{|c|}{ Control } & \multicolumn{3}{|c|}{ Propolis } & \multicolumn{3}{|c|}{ Control } & \multicolumn{3}{|c|}{ Propolis } & \multicolumn{3}{|c|}{ Control } \\
\hline & Min & Mean & Max & Min & Mean & Max & Min & Mean & Max & Min & Mean & Max & Min & Mean & Max & Min & Mean & Max & Min & Mean & Max & Min & Mean & Max \\
\hline [9] & 6.25 & & 12.5 & & & & & & & & & & & & & & & & & & & & & \\
\hline$[21]$ & & & & & & & & & & & & & & & & & & & & 75 & & $\mathrm{c}$ & 512 & \\
\hline$[43]$ & & & & & & & & 384 & & & & & & 358.4 & & & & & & & & & & \\
\hline$[36]$ & & $>1,600$ & & & & & & & & & & & & & & & & & & & & & & \\
\hline$[44]$ & & 500 & & & 8 & & & & & & & & & & & & & & & & & & & \\
\hline$[26]$ & & 400 & & & & & & & & & & & & & & & & & & & & & & \\
\hline \multirow[t]{3}{*}[45]{} & & & & & & & & & & & & & & 1562.5 & & e & $1,562.5$ & & & & & & & \\
\hline & & & & & & & & & & & & & & & & $\mathrm{f}$ & 680.0 & & & & & & & \\
\hline & & & & & & & & & & & & & & & & $\mathrm{g}$ & $1,480.0$ & & & & & & & \\
\hline$[46]$ & 200 & 300 & 400 & & & & & & & & & & & & & & & & & & & & & \\
\hline$[47]$ & 53 & & 106 & & & & & & & & & & & & & & & & & & & & & \\
\hline [48] & 100 & 150 & 200 & & & & & & & & & & & & & & & & & & & & & \\
\hline [49] & & $>1,600$ & & & & & & & & & & & & & & & & & & & & & & \\
\hline Mean & & 758 & & & 8 & & & 384 & & & & & & 960.4 & & & $1,240.8$ & & & 75 & & & 512 & \\
\hline
\end{tabular}

(a) Sanguinarine; (b) itraconazole; (c) chlorhexidine; (d) ketoconazole; (e) caoh2; (f) camphorated paramonochlorophenol; (g) formocresol; (h) fluconazol; (i) meropenem; (j) penicillin g; (k) penicillin; (l) miconazole; (m) tetracycline; (n) metronidazole; (o) erythromycin; (p) clindamycin. 
Table 3. MIC (minimal inhibitory concentration; $\mu \mathrm{g} / \mathrm{mL}$ ) of propolis and control compounds (indicated with different superscript letters).

\begin{tabular}{|c|c|c|c|c|c|c|c|c|c|c|c|c|c|c|c|c|c|c|c|c|c|c|c|c|c|}
\hline \multirow{3}{*}{ Ref. } & \multicolumn{7}{|c|}{ S. mutans } & \multicolumn{6}{|c|}{ P. gingivalis } & \multicolumn{6}{|c|}{ F. nucleatum } & \multicolumn{6}{|c|}{ C. albicans } \\
\hline & \multicolumn{3}{|c|}{ Propolis } & \multicolumn{4}{|c|}{ Control } & \multicolumn{3}{|c|}{ Propolis } & \multicolumn{3}{|c|}{ Control } & \multicolumn{3}{|c|}{ Propolis } & \multicolumn{3}{|c|}{ Control } & \multicolumn{3}{|c|}{ Propolis } & \multicolumn{3}{|c|}{ Control } \\
\hline & Min & Mean & Max & & Min & Mean & Max & Min & Mean & Max & Min & Mean & Max & Min & Mean & Max & Min & Mean & Max & Min & Mean & Max & Min & Mean & Max \\
\hline [21] & & & & & & & & & & & & & & & & & & & & & 150 & & $\mathrm{c}$ & 512 & \\
\hline [50] & & 35 & & & & & & & & & & & & & & & & & & & & & & & \\
\hline [51] & 8 & 20 & 32 & & 0.5 & 2.025 & 4 & & & & & & & & & & & & & & & & & & \\
\hline [35] & & 170 & & $\mathrm{a}$ & & 15 & & & & & & & & & & & & & & & 940 & & $\mathrm{~h}$ & 10 & \\
\hline [43] & & & & & & & & & 294.4 & & & & & & 256 & & & & & & & & & & \\
\hline [36] & & 100 & & & & & & & & & & & & & & & & & & & & & & & \\
\hline [44] & & 125 & & c & 1 & 1.5 & 2 & & & & & & & & & & & & & & & & & & \\
\hline \multirow[t]{2}{*}{ [20] } & & & & & & & & & 256 & & $\mathrm{i}$ & 1 & & & 1024 & & $\mathrm{i}$ & 0.06 & & & & & & & \\
\hline & & & & & & & & & & & $\mathrm{j}$ & 0.03 & & & & & $\mathrm{j}$ & 4 & & & & & & & \\
\hline [26] & & 50 & & & & & & & & & & & & & & & & & & & & & & & \\
\hline \multirow[t]{3}{*}{ [45] } & & & & & & & & & & & & & & & 390.6 & & e & 781.2 & & & & & & & \\
\hline & & & & & & & & & & & & & & & & & $\mathrm{f}$ & 170.0 & & & & & & & \\
\hline & & & & & & & & & & & & & & & & & $\mathrm{g}$ & 371.0 & & & & & & & \\
\hline [46] & 50 & 75 & 100 & & & & & & & & & & & & & & & & & & & & & & \\
\hline$[38]$ & & 200 & & $\mathrm{k}$ & & 0.0922 & & & & & & & & & & & & & & & 90 & & 1 & 5.9 & \\
\hline [52] & 8 & 36 & 64 & & & & & & & & & & & & & & & & & & & & & & \\
\hline [39] & & 0.5 & & $\mathrm{a}$ & & 0.015 & & & & & & & & & & & & & & 4 & 18 & 32 & & & \\
\hline \multirow[t]{6}{*}{ [19] } & & & & $\mathrm{m}$ & & 4 & & & & & & & & & & & & & & & 0.8 & & $\mathrm{~h}$ & 0.01 & \\
\hline & & & & $\mathrm{j}$ & & 0.03 & & & & & & & & & & & & & & & & & & & \\
\hline & & & & $\mathrm{n}$ & & 4 & & & & & & & & & & & & & & & & & & & \\
\hline & & & & o & & 0.5 & & & & & & & & & & & & & & & & & & & \\
\hline & & & & $\mathrm{i}$ & & 1 & & & & & & & & & & & & & & & & & & & \\
\hline & & & & $\mathrm{p}$ & & 0.5 & & & & & & & & & & & & & & & & & & & \\
\hline [47] & 3.3 & 4.95 & 6.6 & & & & & & & & & & & & & & & & & & & & & & \\
\hline [48] & 100 & 150 & 200 & & & & & & & & & & & & & & & & & & & & & & \\
\hline [53] & $\begin{array}{c}3,13 \\
0\end{array}$ & 7,815 & 12,500 & & & & & & & & & & & & & & & & & & & & & & \\
\hline [54] & & & & & & & & & & & & & & & & & & & & & 0.5 & & & & \\
\hline [55] & & 27,470 & & $\mathrm{n}$ & & 37500 & & & & & & & & & & & & & & & & & & & \\
\hline [49] & 25 & 37.5 & 50 & & & & & & & & & & & & & & & & & & & & & & \\
\hline [42] & & & & & & & & 0.01 & 0.056 & 0.1 & & & & & & & & & & & & & & & \\
\hline Mean & & $2,419.3$ & & & & $12,500.5$ & & & 183.5 & & & 0.51 & & & 556.87 & & & 265.3 & & & 199.8 & & & 132 & \\
\hline
\end{tabular}

(a) Sanguinarine; (b) itraconazole; (c) chlorhexidine; (d) ketoconazole; (e) caoh2; (f) camphorated paramonochlorophenol; (g) formocresol; (h) fluconazol; (i) meropenem; (j) penicillin g; (k) penicillin; (l) miconazole; (m) tetracycline; (n) metronidazole; (o) erythromycin; (p) clindamycin. 
In summary, propolis showed a positive antimicrobial effect. However, when compared to a diversity of standard control substances, like established antibiotics, antiseptics and antifungals, propolis was less effective and required higher concentrations than the control compounds.

\section{Discussion}

Most oral diseases are primarily caused, or at least modified, by bacteria that inhabit the oral cavity. Among them, caries and periodontitis represent the most common pathological conditions, which are caused by the biofilm-forming bacteria and yeasts of dental plaque. Accordingly, most of the prophylactic and therapeutic interventions aim to reduce the bacterial load in such a way that oral health can be maintained or obtained. Antimicrobials are useful to support these efforts by effectively inhibiting the formation or removing established biofilms.

Propolis has been used since ancient times as a remedy for the treatment of many diseases in folk medicine. It is considered to be safe in low doses besides its antimicrobial activity [22]. Numerous in vitro studies are available on the antimicrobial capacity of propolis, and therefore, the aim of this review was to gain an overview of these findings, in order to determine if propolis can be considered for further clinical investigations of these. For maintaining a focused question, three microbiological methods were considered, in investigating four oral species, which included the cariogenic S. mutans, the periodontitis-associated $P$. gingivalis and $F$. nucleatum (which can be found in several inflammatory conditions) and the yeast, C. albicans, which is involved in oral candidiasis. In this context, it should also be clarified that neither definitive conclusions about a wider range of pathogens, nor the efficacy of propolis on clinically applicable models can be made from this review. In particular, a starting point for the latter would be the study of the effect of propolis on more complex biofilm models. A. naeslundii would also have been potentially interesting. However only two studies included this bacteria, and therefore, these studies could not be considered in this review. In this context, other potential relevant databases, such as The Biological Abstracts, Chemical Abstracts, Medline, Web of Science, Highwire and Lilacs, could have been helpful. However, since we were focusing more on dental and medical applications and related bacteriology, our search was limited to PubMed. Its use resulted already in a large number of potential literature.

By the single bacterial approach and the narrowed microbiological assays targeted by the present review, the collected data allowed for a ground comparison of the effectiveness of propolis, in comparison to some standard antimicrobial agents, which are designated in this paper as "controls". However, the heterogeneity of the controls ranging from frequently-used antiseptics, like chlorhexidine, to antibiotics still made a direct comparison difficult. Nevertheless, as a principal finding, it could be elaborated that propolis showed a clear antibacterial effect, which was, however, less effective than the investigated control agents and required, in fact, higher concentrations than those (10- to 100-times higher MIC and MBC). The inhibition zones in the agar diffusion test were correspondingly smaller in comparison to the control substances. However, these overall differences could hypothetically be narrower in real-life application, given the fact that the total concentrations of various medicaments must anyway be even greater under clinical conditions than in the planktonic state, in order to obtain a successful microbiological outcome [23]. 
Another matter to consider when comparing these studies is, on the one hand, the large number of control substances used and, on the other hand, the different origin and formulation of propolis. Most of these studies that have assessed propolis come from Brazil (Table 4). Propolis from this origin showed superior effectiveness, compared to others [24-26]. Clearly, the composition of propolis depends upon the vegetation of the area from which it is collected [27]. This natural or intrinsic potential is also influenced by the galenic formulation and preparation, e.g., the use of solvents, like alcohol. Therefore, it is difficult to assess and rate the sole activity of propolis itself in this context.

Table 4. Geographic origin of propolis.

\begin{tabular}{cc}
\hline Number of Publications & Origin of Propolis \\
\hline 14 & Brazil \\
2 & Greece \\
2 & Turkey \\
2 & Laboratory-manufactured \\
1 & Korea \\
1 & Tunisia \\
1 & Argentina and Uruguay \\
1 & Uruguay \\
1 & Czech Republic \\
1 & European-Siberian \\
1 & Irano-Turanian \\
1 & Lithuania \\
1 & Poland \\
1 & China \\
\hline
\end{tabular}

In the obtained literature, sanguinarine is described as another natural product showing an antibacterial effect, exhibiting an effective plaque-inhibiting potential. It is isolated from Sanguinaria canadensis and has been widely used in industrial toothpaste and mouthwash products [28]. The MIC and MBC for sanguinarine against $S$. mutans, as an example, were reported to be 15.6 and $31.3 \mu \mathrm{g} / \mathrm{mL}$, respectively, which was also much higher than the respective values obtained for chlorhexidine, which accounted for 1 and $2 \mu \mathrm{g} / \mathrm{mL}$. Unfortunately, no data regarding the MIC of chlorhexidine was available as a control agent with regard to periodontal bacteria [29]. Stanley and co-workers systematically determined the susceptibility to chlorhexidine of a range of bacteria isolated from subgingival plaque. The modal value of the MIC was found to be $62 \mu \mathrm{g} / \mathrm{mL}$, and $64 \%$ of the strains tested were inhibited at this concentration. A concentration of $250 \mu \mathrm{g} / \mathrm{mL}$ of chlorhexidine inhibited the growth of all bacteria in the 25 subgingival plaque samples investigated [30].

Propolis therefore also displayed an antibacterial potential, although weaker than other conventional pharmaceutical substances testes. However, despite the fact that the antibacterial efficacy of propolis may be somewhat limited, the ongoing search and evaluation of natural products is still warranted [31]. Interestingly, besides its antimicrobial potential, propolis has also been shown to inhibit the adherence of $S$. mutans onto glass, which offers a "preventive" advantage, for instance in terms of biofilm formation and establishment [32]. In one instance, propolis showed antimicrobial activity similar to 
chlorhexidine and even greater than clove or sage extracts in a study using bacteria from the saliva of periodontally healthy subjects and those with chronic periodontitis [33].

\section{Conclusions}

Therefore, propolis has the potential, especially in the case of S. mutans, to develop into an antiseptic agent, but higher concentrations may be required. The product offers an alternative for patients seeking complementary agents and alternatives from synthetic chemicals. Especially for long-term usage, it may also be a valuable option, but the possibility of allergic or other adverse reactions should not be neglected and should be investigated further.

\section{Conflicts of Interest}

The authors declare no conflict of interest.

\section{References}

1. Greenstein, G. Position paper: The role of supra- and subgingival irrigation in the treatment of periodontal diseases.; Research, Science and Therapy Committee of the American Academy of Periodontology. J. Periodontol. 2005, 76, 2015-2027.

2. Slots, J. Low-cost periodontal therapy. Periodontol 2000; 2012, 60, 110-137.

3. Bidault, P.; Chandad, F.; Grenier, D. Risk of bacterial resistance associated with systemic antibiotic therapy in periodontology. J. Can. Dent. Assoc. 2007, 73, 721-725.

4. Slots, J. Selection of antimicrobial agents in periodontal therapy. J. Periodontal Res. 37, 2002, 389-398.

5. Molan, P.C. The potential of honey to promote oral wellness. Gen. Dent. 2001, 49, 584-589.

6. Park, Y.K.; Alencar, S.M.; Agujar, C.L. Botanical origin and chemical composition of Brazilian propolis. J. Agricult. Food Chem. 2002, 50, 2502-2506.

7. Silva, B.B.; Rosalen, P.L.; Cury, J.A.; Ikegaki, M.; Souza, VC.; Estevez, A.; Alencar, SM. Chemical composition and botanical origin of red propolis, a new type of Brazilian propolis. Evid. Based Complement. Alternat. Med. 2008, 103, 487-492.

8. Bosio, K.; Avanzini, C.; D’Avolio, A.; Ozino, O.; Savoia, D. In vitro activity of propolis against Streptococcus pyogenes. Lett. Appl. Microbiol. 2000, 31, 174-177.

9. Drago, L.; Mombelli, B.; de Vecchi, E.; Fassina, M.C.; Tocalli, L.; Gismondo, M.R. In vitro antimicrobial activity of propolis dry extract. J. Chemother. 2000, 12, 390-395.

10. Toreti, V.C.; Sato, H.H.; Pastore, G.M.; Park, Y.K. Recent progress of propolis for its biological and chemical compositions and its botanical origin. Evid. Based Complement. Altern. Med. 2013, doi:10.1155/2013/697390.

11. Salomão, K.; Dantas, A.P.; Borba, C.M.; Campos, L.C.; Machado, D.G.; Aquino Neto, F.R.; de Castro, S.L. Chemical composition and microbicidal activity of extracts from Brazilian and Bulgarian propolis. Lett. Appl. Microbiol. 2004, 38, 87-92. 
12. Kujumgiev, A.; Tsvetkova, I.; Serkedjieva, Y.; Bankova, V.; Christov, R.; Popov, S. Antibacterial, antifungal and antiviral activity of propolis of different geographic origin. J. Ethnopharmacol. 1999, 64, 235-240.

13. Sforcin, J.M.; Fernandes, A., Jr.; Lopes, C.A.; Bankova, V.; Funari, S.R. Seasonal effect on Brazilian propolis antibacterial activity. J. Ethnopharmacol. 2000, 73, 243-249.

14. De Groot, A.C. Propolis: A review of properties, applications, chemical composition, contact allergy, and other adverse effects. Dermatitis 2013, 24, 263-282.

15. Banskota, A.H.; Tezuka, Y.; Kadota, S. Recent progress in pharmacological research of propolis. Phytother. Res. 2001, 15, 561-571.

16. Burdock, G.A. Review of the biological properties and toxicity of bee propolis (propolis). Food Chem. Toxicol. 1998, 36, 347-363.

17. French, G.L. Bactericidal agents in the treatment of MRSA infections-The potential role of daptomycin. J. Antimicrob. Chemother. 2006, 58, 1107-1117.

18. Santos, F.A.; Bastos, E.M.; Uzeda, M.; Carvalho, M.A.; Farias, L.M.; Moreira, E.S.; Braga, F.C. Antibacterial activity of Brazilian propolis and fractions against oral anaerobic bacteria. J. Ethnopharmacol. 2002, 80, 1-7.

19. Santos, F.A.; Bastos, E.M.; Rodrigues, P.H.; de Uzeda, M.; de Carvalho, M.A.; Farias Lde, M.; Moreira, E.S. Susceptibility of Prevotella intermedia/Prevotella nigrescens (and Porphyromonas gingivalis) to propolis (bee glue) and other antimicrobial agents. Anaerobe 2002, 8, 9-15.

20. Santos, F.A.; Bastos, E.M.; Maia, A.B.; Uzeda, M.; Carvalho, M.A.; Farias, L.M.; Moreira, E.S. Brazilian propolis: Physicochemical properties, plant origin and antibacterial activity on periodontopathogens. Phytother. Res. 2003, 17, 285-289.

21. Arslan, S.; Ozbilge, H.; Kaya, E.G.; Er, O. In vitro antimicrobial activity of propolis, BioPure MTAD, sodium hypochlorite, and chlorhexidine on Enterococcus faecalis and Candida albicans. Saudi Med. J. 2011, 32, 479-483.

22. Castaldo, S.; Capasso, F. Propolis, an old remedy used in modern medicine. Fitoterapia 2002, 73, 1-6.

23. Marsh, P.D. Dental plaque: Biological significance of a biofilm and community life-style. J. Clin. Periodontol. 2005, 32, 7-15.

24. Park, Y.K.; Koo, M.H.; Abreu, J.A.; Ikegaki, M.; Cury, J.A.; Rosalen, P.L. Antimicrobial activity of propolis on oral microorganisms. Curr. Microbiol. 1998, 36, 24-28.

25. Koo, H.; Gomes, B.P.; Rosalen, P.L.; Ambrosano, G.M.; Park, Y.K.; Cury, J.A. In vitro antimicrobial activity of propolis and Arnica montana against oral pathogens. Arch Oral. Biol. 2000, 45, 41-48.

26. Koo, H.; Rosalen, P.L.; Cury, J.A.; Ambrosano, G.M.; Murata, R.M.; Yatsuda, R.; Ikegaki, M.; Alencar, S.M.; Park, Y.K. Effect of a new variety of Apis mellifera propolis on mutans Streptococci. Curr. Microbiol. 2000, 41, 192-196.

27. Seidel, V.; Peyfoon, E.; Watson, D.G.; Fearnley, J. Comparative study of the antibacterial activity of propolis from different geographical and climatic zones. Phytother. Res. 2008, 22, 1256-1263.

28. Southard, G.L.; Boulware, R.T.; Walborn, D.R.; Groznik, W.J.; Thorne, E.E.; Yankell, S.L. Sanguinarine, a new antiplaque agent: Retention and plaque specificity. J. Am. Dent. Assoc. 1984, $108,338-341$. 
29. Chung, J.Y.; Choo, J.H.; Lee, M.H.; Hwang, J.K. Anticariogenic activity of macelignan isolated from Myristica fragrans (nutmeg) against Streptococcus mutans. Phytomedicine 2006, 13, 261-266.

30. Stanley, A.; Wilson, M.; Newman, H.N. The in vitro effects of chlorhexidine on subgingival plaque bacteria. J. Clin. Periodontol. 1989, 16, 259-264.

31. World Health Organization (WHO). National Policy on Traditional Medicine and Regulation of Herbal Medicines: Report of a WHO Global Survey; WHO: Geneva, Switzerland, 2005; ISBN 92-4-159323-7.

32. Koo, H.; Vacca Smith, A.M.; Bowen, W.H.; Rosalen, P.L.; Cury, J.A.; Park, Y.K. Effects of Apis mellifera propolis on the activities of streptococcal glucosyltransferases in solution and adsorbed onto saliva-coated hydroxyapatite. Caries Res. 2000, 34, 418-426.

33. Feres, M.; Figueiredo, L.C.; Barreto, I.M.; Coelho, M.H.; Araujo, M.W.; Cortelli, S.C. In vitro antimicrobial activity of plant extracts and propolis in saliva samples of healthy and periodontally-involved subjects. J. Int. Acad. Periodontol. 2005, 7, 90-96.

34. Liberio, S.A.; Pereira, A.L.; Dutra, R.P.; Reis, A.S.; Araújo, M.J.; Mattar, N.S.; Silva, L.A.; Ribeiro, M.N.; Nascimento, F.R.; Guerra, R.N.; et al. Antimicrobial activity against oral pathogens and immunomodulatory effects and toxicity of geopropolis produced by the stingless bee Melipona fasciculata Smith. BMC Complement. Altern. Med. 2011, 11, 108.

35. Popova, M.P.; Chinou, I.B.; Marekov, I.N.; Bankova, V.S. Terpenes with antimicrobial activity from Cretan propolis. Phytochemistry 2009, 70, 1262-1271.

36. Duarte, S.; Koo, H.; Bowen, W.H.; Hayacibara, M.F.; Cury, J.A.; Ikegaki, M.; Rosalen, P.L. Effect of a novel type of propolis and its chemical fractions on glucosyltransferases and on growth and adherence of mutans streptococci. Biol. Pharm. Bull. 2003, 26, 527-531.

37. Malhotra, N.; Rao, S.P.; Acharya, S.; Vasudev, B. Comparative in vitro evaluation of efficacy of mouthrinses against Streptococcus mutans, Lactobacilli and Candida albicans. Oral Health Prev. Dent. 2011, 9, 261-268.

38. Bruschi, M.L.; Lara, E.H.; Martins, C.H.; Vinholis, A.H.; Casemiro, L.A.; Panzeri, H.; Gremião, M.P. Preparation and antimicrobial activity of gelatin microparticles containing propolis against oral pathogens. Drug Dev. Ind. Pharm. 2006, 32, 229-238.

39. Melliou, E.; Chinou, I. Chemical analysis and antimicrobial activity of Greek propolis. Planta. Med. 2004, 70, 515-519.

40. Kartal, M.; Yildiz, S.; Kaya, S.; Kurucu, S.; Topçu, G. Antimicrobial activity of propolis samples from two different regions of Anatolia. J. Ethnopharmacol. 2003, 86, 69-73.

41. Tichy J.; Novak, J. Detection of antimicrobials in bee products with activity against viridans streptococci. J. Altern. Complement. Med. 2000, 6, 383-389.

42. Agarwal, G.; Vemanaradhya, G.G.; Mehta, D.S. Evaluation of chemical composition and efficacy of Chinese propolis extract on Porphyromonas gingivalis and Aggregatibacter actinomycetemcomitans: An in vitro study. Contemp. Clin. Dent. 2012, 3, 256-261.

43. Koru, O.; Toksoy, F.; Acikel, C.H.; Tunca, Y.M.; Baysallar, M.; Uskudar Guclu, A.; Akca, E.; Ozkok Tuylu, A.; Sorkun, K.; Tanyuksel, M.; et al. In vitro antimicrobial activity of propolis samples from different geographical origins against certain oral pathogens. Anaerobe 2007, 13, $140-145$. 
44. Koo, H.; Rosalen, P.L.; Cury, J.A.; Park, Y.K.; Bowen, W.H. Effects of compounds found in propolis on Streptococcus mutans growth and on glucosyltransferase activity. Antimicrob. Agents Chemother. 2002, 46, 1302-1309.

45. Ferreira, F.B.; Torres, S.A.; Rosa, O.P.; Ferreira, C.M.; Garcia, R.B.; Marcucci, M.C.; Gomes, B.P. Antimicrobial effect of propolis and other substances against selected endodontic pathogens. Oral Surg. Oral Med. Oral Pathol. Oral Radiol. Endod. 2007, 104, 709-716.

46. Alencar, S.M.; Oldoni, T.L.; Castro, M.L.; Cabral, I.S.; Costa-Neto, C.M.; Cury, J.A.; Rosalen, P.L.; Ikegaki, M. Chemical composition and biological activity of a new type of Brazilian propolis: Red propolis. J. Ethnopharmacol 2000, 113, 278-283.

47. Castro, M.L.; do Nascimento, A.M.; Ikegaki, M.; Costa-Neto, C.M.; Alencar, S.M.; Rosalen, P.L. Identification of a bioactive compound isolated from Brazilian propolis type 6. Bioorg. Med. Chem. 2009, 17, 5332-5335.

48. Bueno-Silva, B.; Alencar, S.M.; Koo, H.; Ikegaki, M.; Silva, G.V.; Napimoga, M.H.; Rosalen, P.L. Anti-inflammatory and antimicrobial evaluation of neovestitol and vestitol isolated from Brazilian red propolis. J. Agric. Food Chem. 2013, 61, 4546-4550.

49. Da Cunha, M.G.; Franchin, M.; de Carvalho Galvão, L.C.; de Ruiz, A.L.; de Carvalho, J.E.; Ikegaki, M.; de Alencar, S.M.; Koo, H.; Rosalen, P.L. Antimicrobial and antiproliferative activities of stingless bee Melipona scutellaris geopropolis. BMC Complement. Altern. Med. 2013, $13,23$.

50. Kim, M.J.; Kim, C.S.; Kim, B.H.; Ro, S.B.; Lim, Y.K.; Park, S.N.; Cho, E.; Ko, J.H.; Kwon, S.S.; Ko, Y.M.; Kook, J.K. Antimicrobial effect of Korean propolis against the mutans streptococci isolated from Korean. J. Microbiol. 2011, 49, 161-164.

51. Kouidhi, B.; Zmantar, T.; Bakhrouf, A. Anti-cariogenic and anti-biofilms activity of Tunisian propolis extract ans its potential protective effect against cancer cells proliferation. Anaerobe 2010, 16, 566-571.

52. Uzel, A.; Sorkun, K.; Onçağ, O.; Cogŭlu, D.; Gençay, O.; Salih, B. Chemical compositions and antimicrobial activities of four different Anatolian propolis samples. Microbiol. Res. 2005, 160, 189-195.

53. Dziedzic, A.; Kubina, R.; Wojtyczka, R.D.; Kabała-Dzik, A.; Tanasiewicz, M.; Morawiec, T. The antibacterial effect of ethanol extract of polish propolis on mutans streptococci and lactobacilli isolated from saliva. Evid. Based. Complement. Alternat. Med. 2013, 681891.

54. Ramanauskienè, K.; Inkėnienè, A.M.; Petrikaitè, V.; Briedis, V. Total phenolic content and antimicrobial activity of different lithuanian propolis solutions. Evid Based Complement. Alternat Med. 2013, 842985.

55. De Souza Ferreira, S.B.; de Assis Dias, B.R.; Obregón, C.S.; Gomes, C.C.; de Araújo Pereira, R.R.; Ribeiro Godoy, J.S.; Estivalet Svidzinski, T.I.; Bruschi, M.L. Microparticles containing propolis and metronidazole: In vitro characterization, release study and antimicrobial activity against periodontal pathogens. Pharm. Dev. Technol. 2014, 19, 173-180.

(C) 2014 by the authors; licensee MDPI, Basel, Switzerland. This article is an open access article distributed under the terms and conditions of the Creative Commons Attribution license (http://creativecommons.org/licenses/by/3.0/). 